\title{
Pediatric News
}

\section{McCracken Selected as 2005 Yaffe Award Recipient}

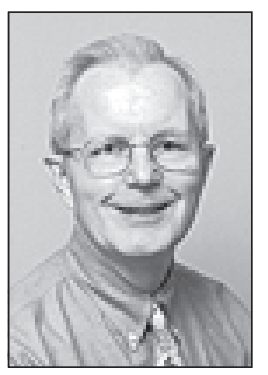

George H. McCracken, Jr., $\mathrm{MD}$, has been selected as the PPAG 2005 recipient of the Sumner J. Yaffe Lifetime Achievement in Pediatric Pharmacology and Therapeutics. Dr. McCracken is Professor of Pediatrics, The GlaxoSmithKline Distinguished Professor of Pediatric Infectious Disease, and The Sarah M. and Charles E. Seay Chair in Pediatric Infectious Diseases at the University of Texas Southwestern Medical Center at Dallas. He received his undergraduate education at Williams College, medical degree from Cornell University Medical College and internship in Medicine and a Residency in Pediatrics at the New York Hospital.

With 437 peer-reviewed manuscripts and 57 book chapters to his credit, Dr. McCracken has made significant contributions to the scientific literature. His research interests include the clinical pharmacology of antimicrobial agents in infants and children and animal and clinical studies of the molecular pathophysiology and treatment of bacterial meningitis and of lower respiratory tract infections. In addition, he has made more than 220 presentations to peer-reviewed National Conferences, and has held the honor of Visiting Professor and Honorary Lecturer at numerous national and international universities. Dr. McCracken is President and Treasurer of the National Pediatric Infectious Diseases Foundation. He has been Chief Editor of The Pediatric Infectious Disease Journal since 1982 when he and Dr. John Nelson started the journal. He is Co-Director of the National Pediatric Infectious Disease Seminar, and Director of Research Rounds, an annual meeting for Infectious Disease Fellows. A fellow of the American Academy of Pediatrics and an Honorary Life Member of the Australian Society for Infectious Diseases, he is a member of the American Society for Microbiology, Society for Pediatric Research, Infectious Diseases Society of America, and the American Pediatric Society.

Since 1968, Dr. McCracken has trained 86 fellows (6 currently) in pediatric infectious diseases, of which $80 \%$ are engaged in active research and training at university-affiliated medical centers and children's hospitals worldwide. In addition, since 1992 he has raised $\$ 4,070,000$ for the Pediatric Infectious Diseases Society to sponsor 51 twoyear fellowship training awards.

Dr. McCracken has received many honors and awards during his career, including the WeinsteinGoldenson Award for Scientific Research from the United Cerebral Palsy Association, Bristol Award for Distinguished Achievements in Infectious Diseases from the Infectious Diseases Society of America, Hoechst-Roussel Award for Outstanding Accomplishments in Antimicrobial Chemotherapy from the American Society for Microbiology, and Outstanding Teacher Award and Distinguished Service Award from the Children's Medical Center in Dallas. In 1998, the American Society for Microbiology established the Annual George H. McCracken Infectious Disease Fellow Award in recognition of his contributions to the Interscience Conference on Antimicrobial Agents and Chemotherapy and to the American Society for Microbiology. In 2001, he was the recipient of the Distinguished Physician Award for lifetime achievements in research and training from the Pediatric Infectious Diseases Society. In April 2003, he received the Bicentennial Medal from his alma mater, Williams College, Williamstown, Massachusetts, for distinguished accomplishments in pediatric medicine. He received in 2003 the Mentor Award from the Infectious Diseases Society of America for recognition of a lifetime of service as a mentor for infectious disease professionals. In November 2003, he was inducted into the Ambassador David M. Walters International Pediatric Hall of Fame, Miami Children's Hospital Foundation for outstanding contributions in the area of pediatric infectious disease and antimicrobial therapy. In March 2004 Dr. McCracken received the Maxwell Finland Award for scientific achievements from the National Foundation for Infectious Diseases. In October 2004 Dr McCracken was the first recipient of the Lifetime Contribution to Education in Infectious Disease from the Section on Infectious Disease of the American Academy of Pediatrics.

Dr. McCracken will present the Yaffe Award Lecture during the October Annual Meeting of the Pediatric Pharmacy Advocacy Group (www.ppag.org). 


\section{FDA Statement on Adderall- Sudden Death in Children}

BETHESDA, MD, February 9, 2005 - Health Canada has suspended marketing of Adderall XR (extended release) from the Canadian market due to concern about reports of sudden unexplained death (SUD) in children taking Adderall and Adderall XR. SUD has been associated with amphetamine abuse and reported in children with underlying cardiac abnormalities taking recommended doses of amphetamines, including Adderall and Adderall XR. In addition, a very small number of cases of SUD have been reported in children without structural cardiac abnormalities taking Adderall. At this time, FDA cannot conclude that recommended doses of Adderall can cause SUD, but is continuing to carefully evaluate these data. As a precaution, FDA recommends that Adderall products not be used in children or adults with structural cardiac abnormalities.

A review of the data from the FDA's Adverse Event Reporting System database for the years 1999 through 2003 identified 12 cases of sudden death in pediatric patients ( 1 to 18 years of age) who were being treated for ADHD with Adderall or Adderall XR (see table for description of cases).

Five of the 12 pediatric sudden death cases pediatric sudden death cases described cardiac risk factors including undiagnosed cardiac abnormalities (e.g., aberrant origin of coronary artery, bicuspid aortic valve, idiopathic hypertrophic subaortic stenosis). Seven occurred in children without such abnormalities, including 1 with a positive family history of ventricular arrhythmia. Several of the cases were complicated by other illness, and very rigorous exercise. Unusual and unexplained accumulation of drug resulting in toxic levels during usual therapeutic dosing also appears to have played a role in several of the pediatric sudden death cases. The rare occurrence of sudden death during stimulant therapy of ADHD deserves continued evaluation. SUD as a possible effect of amphetamines should be considered in the assessment of benefit versus risk during therapeutic decision-making for individual patients. In the pediatric population, potential risk factors include cardiac abnormalities that may be undiagnosed, positive family history for ventricular arrhythmias, and as yet unidentified factors that may cause excessive levels of stimulant to accumulate in children who are taking apparently normal doses.

An update and further analyses of the data are currently in progress. FDA is aware of Health Canada's decision to suspend sales, but not revoke the approval in Canada, of the drug Adderall as a treatment for Attention Deficit and Hyperactivity Disorder (ADHD). FDA has been in close consultation with the Canadian authorities regarding the basis for their action. FDA does not feel that any immediate changes are warranted in the FDA labeling or approved use of this drug based upon its preliminary understanding of Health Canada's analyses of adverse event reports and FDA's own knowledge and assessment of the reports received by the agency. As with any drug, FDA will continue to carefully assess any new data that emerges which significantly affects the safety profile of this drug and will take immediate, appropriate action to promote the public health and make the public aware of its findings.

Characteristics of domestic pediatric SUD cases reported during past five years $(n=12)^{\star}$

\begin{tabular}{l|l}
\hline Age & 7 -16 years (mean 12. years) \\
\hline Gender & 12 male, 0 female \\
\hline Suspect drug & Adderall or Adderall XR \\
\hline Total daily dose & $10 \mathrm{mg}(1), 20 \mathrm{mg} \mathrm{(5),30} \mathrm{mg} \mathrm{(1),40} \mathrm{mg} \mathrm{(1),50} \mathrm{mg} \mathrm{(1),} \mathrm{NR} \mathrm{(3)}$ \\
\hline Duration of therapy & 1 day - 8 years (range) \\
\hline Autopsy & yes (11), not mentioned or not done (1) \\
\hline Cardiac structural abnormalities & $\begin{array}{l}\text { aberrant origin of coronary artery (1), idiopathic hypertrophic subaortic stenosis (1), } \\
\text { bicuspid aortic valve (1), cardiac hypertrophy (2) }\end{array}$ \\
\hline Other risk factors & $\begin{array}{l}\text { Unexplained increase or toxic amphetamine level (2), family history of ventricular } \\
\text { arrhythmia (1), extreme exercise and dehydration (1) }\end{array}$ \\
\hline Concomitant meds & none mentioned (9), 1 med (3) \\
\hline Year reported & $1999(0), 2000$ (2), 2001 (6), 2002 (2), 2003 (2) \\
\hline
\end{tabular}

*numbers in parentheses represent count of cases. 


\section{Gregory Named New Administrative Director at Vanderbilt Children's Hospital}

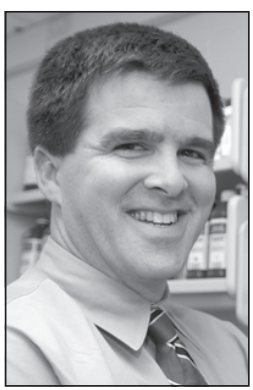

David Gregory, PharmD, BCPS, has been named an administrative director at the Monroe Carell Jr. Children's Hospital at Vanderbilt, Nashville, Tennessee. In his new capacity, Dr. Gregory will oversee the dietary, pharmacy, rehabilitation, biomedical and laboratory departments at the

Children's Hospital.

He received his bachelor's and doctorate degrees in pharmacy from the University of Mississippi. Dr. Gregory began his professional career as a staff pharmacist at Vanderbilt University Medical Center (VUMC) where he eventually became director of the Children's Hospital pharmacy and assistant director of the VUMC. He is a long-standing member of the Pediatric Pharmacy Advocacy Group and a past board chairman. He is also a member of American Society of Health-System Pharmacists and American College of Clinical Pharmacy. 